\title{
Low-Loss, Compact, and Polarization Independent PHASAR Demultiplexer Fabricated by Using a Double-Etch Process
}

\author{
J. H. den Besten, M. P. Dessens, C. G. P. Herben, Associate Member, IEEE, X. J. M. Leijtens, F. H. Groen, \\ M. R. Leys, and M. K. Smit
}

\begin{abstract}
A compact low-loss polarization independent $8 \times 8$ PHASAR demultiplexer is presented. Device size is $0.93 \times 0.75$ $\mathrm{mm}^{2}$. On-chip losses are less than $4 \mathrm{~dB}$ and crosstalk is better than $-20 \mathrm{~dB}$. The device is suitable for integration with electro-optical switches for application in integrated optical crossconnects, add-drop multiplexers and multiwavelength lasers.
\end{abstract}

Index Terms-Demultiplexer, integrated optics, PHASAR, semiconductor waveguides, wavelength-division multiplexing (WDM).

\section{INTRODUCTION}

$\mathbf{P}$ HASED-ARRAY demultiplexers [1] are important components in multiwavelength lasers (MWLs) [2], [3] and integrated wavelength-selective switches such as add-drop multiplexers (ADMs) [4] and optical crossconnects (OXCs) [5], [6]. The increasing amount of components integrated on a single chip results in severe demands on wafer uniformity and processing. These demands can be relaxed by using compact components.

Compact PHASAR-demultiplexers have been reported with high-contrast nonbirefringent waveguides [7]-[10] or high-contrast waveguides with a birefringence compensation [11].

Due to the high contrast of the deeply etched waveguide structure used in compact PHASARs, the losses of these devices are high, typically more than $7 \mathrm{~dB}$. This is caused by the starcouplers, where the deep etch causes a large discontinuity. Van Dam [12] demonstrated a double etch technique to reduce the losses at the junction between the starcoupler and the array guides. Vreeburg [13] reported a low-loss PHASAR in a shallowly etched waveguide structure. Extending the technique as proposed in [12] Herben [14] reported a PHASAR in which the shallowly etched low-loss star-coupler of [13] was combined with the deeply etched compact bends of [11] and [15] using a double etch process. The result was a PHASAR that was both

Manuscript received April 27, 2001; revised September 10, 2001. This work was supported by the ACTS Project AC332 APEX.

J. H. den Besten was with the Opto-Electronic Devices Group, Faculty of Information Technology and Systems, Delft University of Technology, NL-2600 GA, Delft, The Netherlands. He is now with Eindhoven University of Technology, 56 GA Eindhoven, The Netherlands (e-mail: j.h.denbesten@its.tudelft.nl).

M. P. Dessens and C. G. P. Herben are with ThreeFive Photonics, 2629 HG Delft, The Netherlands.

X. J. M. Leijtens, M. R. Leys and M. K. Smit are with Eindhoven University of Technology, 56 GA Eindhoven, The Netherlands.

F. H. Groen is with the Faculty of Applied Sciences, Delft University of Technology, 2600 GA Delft, The Netherlands.

Publisher Item Identifier S 1041-1135(02)00016-2.

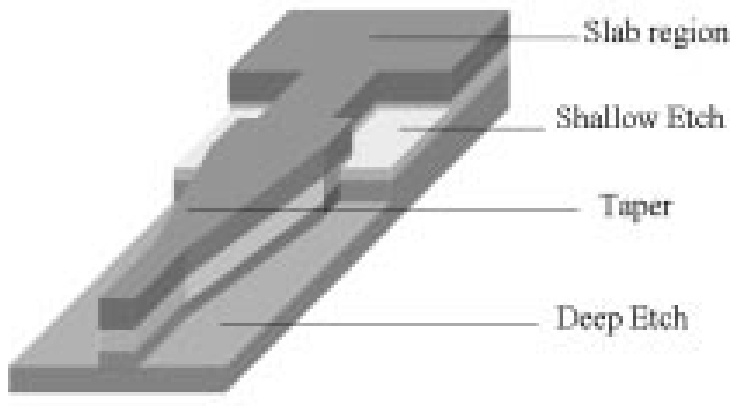

Fig. 1. Shallowly and deeply etched waveguides combined. For alignment tolerance, the waveguide widening is designed $2.5 \mu \mathrm{m}$ away from the transition between the different etch depths. The widening optimizes the coupling between the two mode profiles.

compact and had low losses. This PHASAR had an orthogonal geometry with a large number of straight-curve transitions. Here, we present a PHASAR made by applying the double-etch technique to the simpler geometry of the PHASARs of [11] and [13]. This geometry reduces the number of straight-curve transitions as compared to [14], which will reduce insertion loss.

\section{DESIGN}

We have designed an eight-channel PHASAR using 400-GHz channel spacing $(3.2 \mathrm{~nm}$ at $1550 \mathrm{~nm})$ and a free-spectral-range of $35 \mathrm{~nm}$. The minimal bending radius used for the array waveguides was $100 \mu \mathrm{m}$, which is possible using deeply etched array guides. The PHASAR was designed for a ridge waveguide structure consisting of a 720 -nm-thick InGaAsP waveguide layer (bandgap wavelength $1.25 \mu \mathrm{m}$ ) with a $1.2-\mu \mathrm{m}$-thick InP cladding layer.

The PHASAR uses 3- $\mu \mathrm{m}$-wide and $40-\mu \mathrm{m}$-long shallowly etched guides to couple light out of the slab region, as shown in Fig. 1 for a single waveguide, in such a way that the waveguide-to-waveguide distance slowly increases and the mutual coupling gradually decreases.

These guides are followed by tapers of $50 \mu \mathrm{m}$ length that bring down the width from $3.5 \mu \mathrm{m}$ (the $0.5 \mu \mathrm{m}$ extra width compensates for the higher confinement of the deeply etched guides) to $1.7 \mu \mathrm{m}$ (see Fig. 1). At this width the propagation constant of the fundamental mode is polarization independent and higher order modes are strongly attenuated in bends. This avoids the need for additional polarization compensation. 


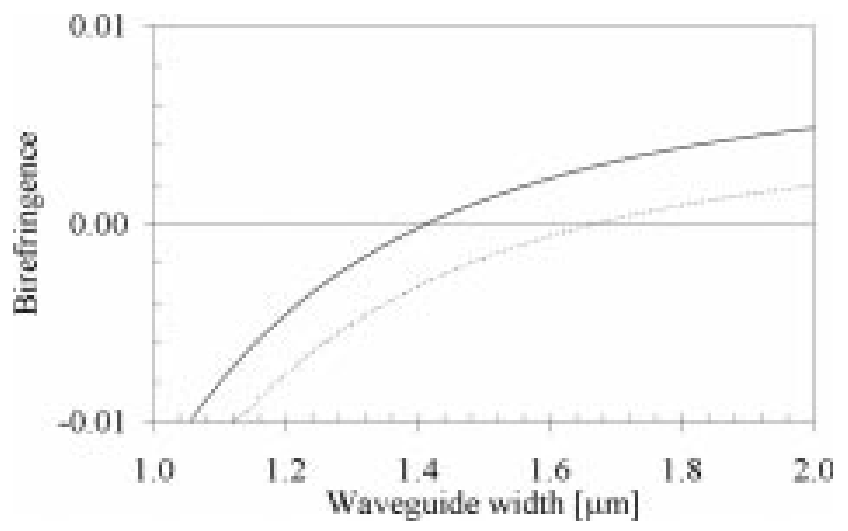

Fig. 2. Birefringence as a function of the waveguide width for the deep etched waveguide structure. The solid line corresponds to a 500-nm filmlayer with $\lambda_{\text {bandgap }}=1.3 \mu \mathrm{m}$, the dashed line represents a $720-\mathrm{nm}$ film layer with $\lambda_{\text {bandgap }}=1.25 \mu \mathrm{m}$.

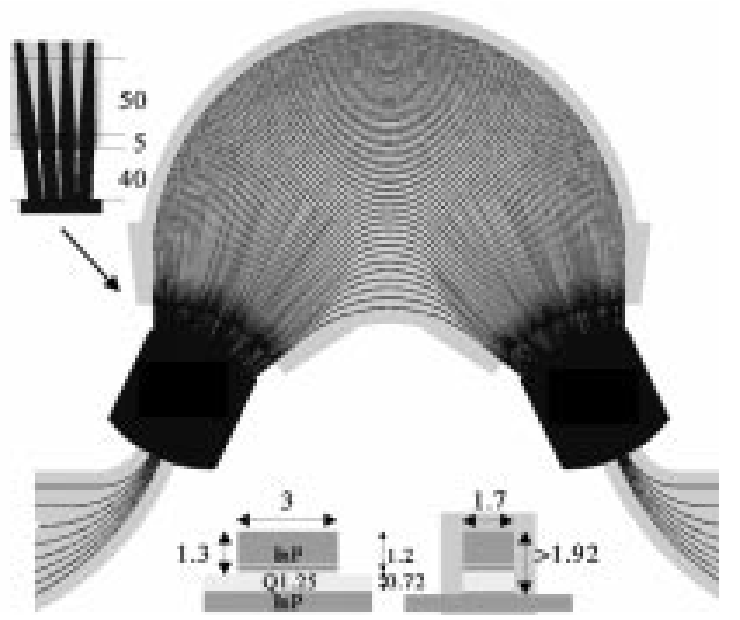

Fig. 3. Mask layout and layerstack of the PHASAR. The shaded area indicates the deeply etched regions. In the top left corner inset an enlargement of the star coupler array junction is given. Numbers are in micrometers.

Nonbirefringence in deeply etched waveguides relies on the waveguide having the correct width. Simulations indicate that waveguides made in the $Q 1.25$ layerstack used here are more tolerant to variations in width than waveguides made in the Q1.3 material, as used in [11] and [14] (see Fig. 2).

The mask layout of the PHASAR is depicted in Fig. 3.

\section{FABRICATION}

The PHASAR was fabricated in a CBE-grown layerstack as shown in Fig. 3. A $100 \mathrm{~nm}$ thick PECVD-SiN layer served as an etching mask for the waveguides. The pattern was defined using contact illumination with positive photoresist and transferred to the SiN-layer by $\mathrm{CHF}_{3}$ reactive ion etching. The waveguides were etched employing an optimized $\mathrm{CH}_{4}-\mathrm{H}_{2}$ etching and $\mathrm{O}_{2}$ descumming process [16]. After the etch depth for the shallow region was reached, part of the wafer was covered with positive photoresist using contact illumination. The photoresist served as a mask for the deep etch that was performed again using a

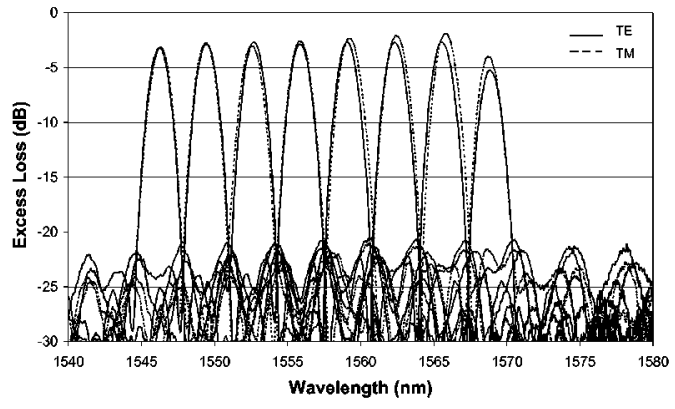

Fig. 4. Spectral response of the PHASAR for all eight channels and both polarization states.

$\mathrm{CH}_{4}-\mathrm{H}_{2}$ etching and $\mathrm{O}_{2}$ descumming process, but this time optimized for photoresist masking.

\section{EXPERIMENTS}

The PHASAR was measured using the spontaneous emission spectrum of an EDFA as a broad-band light source and a polarizer to select the polarization state. Light was coupled into the antireflection (AR)-coated chip using microscope objectives, then coupled out of the waveguides by a single-mode lensed fiber and analyzed with an HP optical spectrum analyzer.

Straight shallowly etched reference waveguides with a width of $3 \mu \mathrm{m}$ showed a propagation loss of 3.0 and $3.5 \mathrm{~dB} / \mathrm{cm}$ for TEand TM-polarization, respectively, which is slightly higher than usual for these waveguides.

Fig. 4 shows the measured spectral response of the PHASAR. The loss performance is equal to [14], while the crosstalk has improved (better than $-20 \mathrm{~dB}$ ). On-chip losses are lower than $4 \mathrm{~dB}$ for both polarization states, except for the last channel. This confirms the loss-reduction by the double-etch transition compared to the completely deeply etched phased array as mentioned in [14]. Similar PHASAR's made using a Q1.3 film layer had even lower losses, but showed larger polarization dependence and poorer crosstalk performance. This confirms our conclusion that $Q 1.25$ material leads to more tolerant designs than $Q 1.3$ material.

The length of the PHASAR measured through the central arm is $1381 \mu \mathrm{m}$, which is $150 \mu \mathrm{m}$ shorter than that of the PHASAR with the orthogonal geometry in [14]. This shorter length gives a loss-reduction of $0.05 \mathrm{~dB}$. Because the three extra straight-curve transitions in the latter PHASAR give a total loss of $0.6 \mathrm{~dB}$, the insertion loss of the PHASAR presented in this letter should be reduced by $0.65 \mathrm{~dB}$. Because of rough sidewalls this reduction was not observed, however.

An eight-channel phased array made in a similar way as the one in [13] was used in a dilated cross connect presented in [17]. The size of this demultiplexer was $1.8 \times 3.1 \mathrm{~mm}^{2}$. That is roughly four times as big in area as the PHASAR presented here, mainly because of the polarization compensating triangle and larger bending radii.

Furthermore, the PHASAR shows good polarization independence, which was achieved without trimming. Residual polarization dispersion of most channels is smaller than $0.2 \mathrm{~nm}$. Channel uniformity for the first seven channels is better than $1 \mathrm{~dB}$. 


\section{CONCLUSION AND DiscuSSION}

A compact polarization independent PHASAR demultiplexer has been reported. The device was realized in a waveguide structure similar to that used in ADMs and OXCs earlier reported. On-chip losses are less than $4 \mathrm{~dB}$, which is slightly higher than results previously reported due to increased waveguide edge roughness. Polarization independence is achieved without compensation or trimming, using nonbirefringent waveguides. Crosstalk is better than $-20 \mathrm{~dB}$. Device size is $0.93 \times 0.75 \mathrm{~mm}^{2}$. Its compactness relaxes the demands on wafer uniformity and processing, which will become important as more components are to be integrated.

\section{ACKNOWLEDGMENT}

A. van Langen and A. Looyen are acknowledged for EBPG mask fabrication and AR coating, respectively.

\section{REFERENCES}

[1] M. K. Smit and C. van Dam, "PHASAR-based WDM-devices: Principles, design, and applications," IEEE J. Select. Topics Quantum Electron., vol. 2, pp. 236-250, June 1996.

[2] P. J. Harmsma, C. A. Verschuren, M. R. Leys, H. Vonk, and Y. S. Oei, "Phased array multi-wavelength lasers fabricated using selective area chemical beam epitaxy," in Proc. IEEE/LEOS Symp. Benelux Chap. (IEEE/LEOS'99), Mons, Belgium, Nov. 15, 1999, pp. 61-64.

[3] C. R. Doerr, C. H. Joyner, and L. W. Stulz, "40-wavelength rapidly digitally tunable laser," IEEE Photon. Technol. Lett., vol. 11, pp. 1348-1350, Nov. 1999.

[4] C. G. M. Vreeburg, T. Uitterdijk, Y. S. Oei, M. K. Smit, F. H. Groen, E. G. Metaal, P. Demeester, and H. J. Frankena, "First InP-based reconfigurable integrated add-drop multiplexer," IEEE Photon. Technol. Lett., vol. 9, pp. 191-193, Feb. 1997.

[5] C. G. P. Herben, C. G. M. Vreeburg, D. H. P. Maat, X. J. M. Leijtens, Y. S. Oei, F. H. Groen, J. W. Pedersen, P. Demeester, and M. K. Smit, "A compact integrated InP-based single-PHASAR optical crossconnect," IEEE Photon. Technol. Lett., vol. 10, pp. 678-680, May 1998.
[6] C. G. P. Herben, D. H. P. Maat, X. J. M. Leijtens, M. R. Leys, Y. S. Oei, and M. K. Smit, "Polarization independent cross-connect on InP," IEEE Photon. Technol. Lett., vol. 11, pp. 1599-1601, Dec. 1999.

[7] M. Kohtoku, H. Sanjoh, S. Oku, Y. Kadota, Y. Yoshikuni, and Y. Shibata, "InP-based 64-channel arrayed waveguide grating with $50 \mathrm{GHz}$ channel spacing and up to $-20 \mathrm{~dB}$ crosstalk," Electron. Lett., vol. 33, no. 21, pp. 1786-1787, October 1997.

[8] B. H. Verbeek, A. A. M. Staring, E. J. Jansen, R. van Roijen, J. J. M. Binsma, T. van Dongen, M. R. Amersfoort, C. van Dam, and M. K. Smit, "Large bandwidth polarization independent and compact 8 channel PHASAR demultiplexer/filter," in Proc. Optical Fiber Communication (OFC'94) Conf.. San Jose, CA, 1994, pp. 63-66.

[9] H. Bissessur, P. Pagnod-Rossiaux, R. Mestric, and B. Martin, "Extremely small polarization independent PHASAR demultiplexers on InP," IEEE Photon. Technol. Lett., vol. 8, pp. 554-556, Apr. 1996.

[10] R. Mestric, M. Renaud, B. Martin, and F. Gaborit, "Up to 16 channel phased-array wavelength demultiplexers on InP with -20 dB crosstalk," in Proc. 8th Eur. Conf. Integrated Optics (ECIO'97), Stockholm, Sweden, Apr. 1997, pp. 264-267.

[11] C. G. P. Herben, X. J. M. Leijtens, F. H. Groen, I. Moerman, and M. K. Smit, "Ultra-compact polarization independent PHASAR demultiplexer," in Proc. Eur. Conf. Optical Communications (ECOC'98), Madrid, Spain, Sept. 1998, pp. 125-126.

[12] C. van Dam, A. A. M. Staring, E. J. Jansen, J. J. M. Binsma, T. van Dongen, M. K. Smit, and B. H. Verbeek, "Loss reduction for phased-array demultiplexers using a double etch technique," in Integrated Photonics Research (IPR'96), Boston, MA, Apr. 29-May 2, 1996, pp. 52-55.

[13] C. G. M. Vreeburg, C. G. P. Herben, X. J. M. Leijtens, M. K. Smit, F. H. Groen, J. J. G. M. van der Tol, and P. Demeester, "A low-loss 16-channel polarization dispersion compensated PHASAR demultiplexer," IEEE Photon. Technol. Lett., vol. 10, pp. 382-384, Mar. 1998.

[14] C. G. P. Herben, X. J. M. Leijtens, F. H. Groen, and M. K. Smit, "Low-loss and compact phased-array demultiplexers using a double etch process," in Proc. 9th Conf. Integr. Opt. (ECIO '99), Torino, Italy, Apr. 14-16, 1999, pp. 211-214.

[15] L. H. Spiekman, Y. S. Oei, E. G. Metaal, F. H. Groen, I. Moerman, and M. K. Smit, "Extremely small multimode interference couplers and ultrashort bends on InP by deep etching," IEEE Photon. Technol. Lett., vol. 6, pp. 1008-1010, Aug. 1994.

[16] Y. S. Oei, L. H. Spiekman, F. H. Groen, I. Moerman, E. G. Metaal, and J. W. Pedersen, "Novel RIE-process for high quality InP-based waveguide structures," in Proc. 7th Eur. Conf. Integrated Optics (ECIO'95), Delft, The Netherlands, Apr. 1995, pp. 205-208.

[17] C. G. P. Herben, D. H. P. Maat, X. J. M. Leijtens, M. R. Leys, Y. S. Oei, and M. K. Smit, "Polarization independent dilated WDM cross-connect on InP," IEEE Photon. Technol. Lett., vol. 11, pp. 1599-1601, Dec. 1999. 